\title{
SUPERIOR HEPATIC MITOCHONDRIAL OXIDATION-REDUCTION STATE IN NORMOTHERMIC CARDIOPULMONARY BYPASS
}

Kazuhiro Hashimoto, MD

Tatsuumi Sasaki, MD

Takashi Hachiya, MD

Katsuhisa Onoguchi, MD

Hiromitsu Takakura, MD

Motohiro Oshiumi, MD

Shigeyuki Takeuchi, MD
Objective: This study is the first comparative investigation of hepatic blood flow and oxygen metabolism during normothermic and hypothermic cardiopulmonary bypass.

Methods: Twenty-four patients undergoing coronary bypass operations were randomly divided into 2 groups according to their perfusion temperatures, either normothermia $\left(36^{\circ} \mathrm{C}\right)$ or hypothermia $\left(30^{\circ} \mathrm{C}\right)$. The clearance of indocyanine green was measured at 3 points. Arterial and hepatic venous ketone body ratios (an index of mitochondrial redox potential) and hepatic venous saturation were measured.

Results: Hepatic blood flow in both groups was identical before, during, and after cardiopulmonary bypass (normothermia, $499 \pm 111,479 \pm 139$, and 563 $\pm 182 \mathrm{~mL} / \mathrm{min}$, respectively; hypothermia, $476 \pm 156,491 \pm 147$, and $560 \pm$ $202 \mathrm{~mL} / \mathrm{min}$, respectively). The hepatic venous saturation levels were significantly lower during cardiopulmonary bypass in the normothermic group (normothermia, $41 \% \pm 13 \%$; hypothermia, $61 \% \pm 18 \% ; P<.01$ ), indicating a higher level of oxygen extraction use. The arterial ketone body ratio in the hypothermic group decreased severely after the onset of cardiopulmonary bypass $(P<.01)$ and did not return to its subnormal value $(>0.7)$ until the second postoperative day. However, the reduction in arterial ketone body ratio was less severe in the normothermic group. The difference in hepatic venous ketone body ratios was more obvious, and the hepatic venous ketone body ratios in the normothermic group were statistically superior to those of the hypothermic group throughout the course $(P<.05-.01)$.

Conclusions: Normothermic cardiopulmonary bypass provides adequate liver perfusion and results in a better hepatic mitochondrial redox potential than hypothermic cardiopulmonary bypass. Because arterial ketone body ratios reflect hepatic energy potential, normothermia was considered to be physiologically more advantageous for hepatic function. ( $\mathrm{J}$ Thorac Cardiovasc Surg 2001;121:1179-86)
$T^{\mathrm{h}}$ he condition of patients who have a long history of congestive heart failure is sometimes complicated by hepatic dysfunction. Acute aggravation of liver function, characterized by sharp increases in the serum concentrations of transaminases and bilirubin, is infrequent but does occasionally occur after cardiac operations.

From the Department of Cardiovascular Surgery, Saitama Cardiovascular and Respiratory Center, Saitama-ken, Japan.

Supported by the institutional research fund of Saitama Cardiovascular and Respiratory Center.

Copyright (C) 2001 by The American Association for Thoracic Surgery

0022-5223/2001 $\$ 35.00+0 \quad \mathbf{1 2 / 1 / 1 1 3 5 9 9}$

doi:10.1067/mtc.2001.113599
The risk of possible hepatic failure complicates the decision to proceed with surgery in these patients. The preoperative condition of the liver is the most influential factor. ${ }^{1}$ However, the severity of postoperative liver damage is also strongly influenced by cardiopulmonary bypass (CPB) conditions, such as the perfusion pressures and the duration of the CPB., ${ }^{1,2}$ Therefore, adequate perfusion of the liver and the maintenance of energy charge potentials in hepatocytes are also considered to be important during CPB.

Hypoperfusion of the liver during CPB has always been considered as a cause of liver damage, but only a few clinical hemodynamic studies focusing on hepatic blood flow and hepatic oxygen metabolism have been 
Table I. Patient profile

\begin{tabular}{lcc}
\hline & $\begin{array}{c}\text { Normothermia } \\
(n=12)\end{array}$ & $\begin{array}{c}\text { Hypothermia } \\
(n=12)\end{array}$ \\
\hline Age (y) & $66 \pm 7$ & $68 \pm 7$ \\
Sex (M/F) & $11 / 1$ & $10 / 2$ \\
Height (cm) & $162 \pm 7$ & $159 \pm 9$ \\
Body weight (kg) & $65 \pm 7$ & $63 \pm 9$ \\
CPB time (min) & $140 \pm 30$ & $148 \pm 31$ \\
Aortic clamp time (min) & $116 \pm 31$ & $113 \pm 35$
\end{tabular}

No significance between 2 groups.

performed..$^{3-6}$ The arterial ketone body ratio (AKBR, the ratio of acetoacetate/3-hydroxybutyrate) reflects the mitochondrial oxidation-reduction (redox) potential $^{7}$ and has been proposed to be an indicator not only of liver dysfunction, but also of dysfunction throughout the entire body. ${ }^{7-11}$ The effect of different CPB perfusion temperatures on AKBR has not been examined.

This study was designed (1) to investigate the relation between perfusion temperature and hepatic blood flow and between perfusion temperature and hepatic venous oxygen saturation during $\mathrm{CPB}$ and (2) to clarify how hepatic mitochondrial function is affected by the perfusion temperature during and after $\mathrm{CPB}$.

\section{Subjects and methods}

Twenty-four patients undergoing elective coronary bypass surgery were selected after we had obtained the approval of our institution's ethics committee and had received the written informed consent of the patients. None of the patients had congestive heart failure or liver disease. The patients were randomly selected by the perfusionists and divided into 2 groups (12 patients in each group) according to their CPB perfusion temperature, either normothermic $\left(36^{\circ} \mathrm{C}\right)$ or hypothermic $\left(30^{\circ} \mathrm{C}\right)$. Two surgeons performed the operations, and surgeons were not informed of the perfusion temperature.

Anesthesia was induced by intravenous injection of fentanyl $(10 \mu \mathrm{g} / \mathrm{kg})$, vecuronium $(0.2 \mathrm{mg} / \mathrm{kg})$, and midazolam $(0.05 \mathrm{mg} / \mathrm{kg})$, and each patient was intubated. Intravenous infusion of propofol $\left(4 \mathrm{mg} \cdot \mathrm{kg}^{-1} \cdot \mathrm{h}^{-1}\right)$ was then commenced and continued until the end of operation. The total dose of fentanyl used during operation was 25 to $30 \mu \mathrm{g} / \mathrm{kg}$. Once the patient was anesthetized, a pulmonary artery catheter (Vigilance Swan-Ganz CCO Thermodilution Catheter; Baxter Healthcare Corp, Irvine, Calif) was inserted through the right internal jugular vein. A hepatic catheter for obtaining blood samples from the hepatic vein was inserted through the left or right femoral vein. The position of the catheter was verified radiographically. The $\mathrm{CPB}$ was performed with a nonpulsatile flow at the constant flow rate, around $2.5 \mathrm{~L}$. $\mathrm{min}^{-1} \cdot \mathrm{m}^{-2}$, irrespective of the perfusion temperature. The patients' arterial blood gases were monitored by alpha-stat control. A membrane oxygenator with hollow polypropylene fibers and polyvinyl chloride tubing was used in both groups.
The prime volumes were the same in both groups and consisted of $1600 \mathrm{~mL}$ of electrolyte solution, $50 \mathrm{~mL}$ of $7 \%$ sodium bicarbonate, and $20 \mathrm{~g}$ of mannitol. The hematocrit level was maintained at more than $20 \%$ throughout the CPB, with blood added as necessary. The perfusion pressures were maintained at 60 to $70 \mathrm{~mm} \mathrm{Hg}$ in both groups. Phenylephrine and nitroglycerin were used to control the pressure during the CPB. A cold blood cardioplegic solution was delivered antegradely and retrogradely. The pericardial well was soaked with cold saline solution (without ice) for topical cooling. All anastomoses in the coronary bypass operation, proximal and distal, were performed during single aortic clamping.

\section{Measurements}

Hepatic blood flow. The cardiac output was measured 3 times at 5-minute intervals during the pre-CPB and the post$\mathrm{CPB}$ periods. The values were then averaged. During $\mathrm{CPB}$ the perfusion flow of the CPB machine was recorded.

The clearance of indocyanine green (ICG) ${ }^{12}$ was measured 3 times during the following periods: (1) after the induction of anesthesia (before CPB), (2) during CPB, and (3) after the cessation of CPB. An ICG dose of $6 \mathrm{mg}$ was first introduced by intravenous bolus injection before and after $\mathrm{CPB}$ or directly into the pump-oxygenator during CPB. After the bolus injection, ICG was continuously injected at a speed of 1 $\mathrm{mg} / \mathrm{min}$. Blood samples were taken from the peripheral arterial and hepatic venous lines at 10,20, and 30 minutes after the bolus injection. The blood was immediately transferred to empty tubes and centrifuged for 15 minutes at $1700 \mathrm{~g}$. The absorbance of the plasma samples was read spectrophotometrically at 805 and $900 \mathrm{~nm}$, the absorbance at $900 \mathrm{~nm}$ being used to correct for turbidity. The concentration of ICG was calculated from the corrected absorbance at $805 \mathrm{~nm}$ by means of a standard curve constructed from human plasma containing known concentrations of ICG. Hepatic blood flow was calculated by means of the following formula: Hepatic blood flow $(\mathrm{mL} / \mathrm{min})=\mathrm{I} /(\mathrm{Ca}-\mathrm{Cv}) \times 100 /(100-\mathrm{Ht})$, where $\mathrm{I}$ is the speed of the ICG injection ( $\mathrm{mg} / \mathrm{min}), \mathrm{Ca}$ is the mean concentration of arterial ICG $(\mathrm{mg} / \mathrm{mL}), \mathrm{Cv}$ is the mean concentration of hepatic venous ICG $(\mathrm{mg} / \mathrm{mL})$, and $\mathrm{Ht}$ is the hematocrit value (\%). The results were expressed as the absolute flow value, the average of 3 measurements $(\mathrm{mL} / \mathrm{min})$, and a percentage of the cardiac output.

Arterial and hepatic ketone body ratios. Arterial and hepatic venous samplings to measure the AKBR and hepatic venous ketone body ratios (HKBR) were performed at 9 time points: (1) after the induction of anesthesia (baseline data), (2) 10 minutes after the initiation of the $\mathrm{CPB}$, (3) 60 minutes after the initiation of the $\mathrm{CPB}$, (4) during the warming period in the hypothermic group or at the time of aortic unclamping in the normothermic group, (5) at the end of CPB, (6) at the time of admission to the intensive care unit (ICU), (7) 6 hours after the ICU admission, (8) first postoperative day, and (9) second postoperative day. The commercially available Ketorex kit (Sanwa Kagaku Kenkyusho Co, Ltd, Nagoya, Japan) was used to measure the ketone body ratios. Acetoacetate and 3-hydroxybutyrate concentrations were measured enzymatically. 


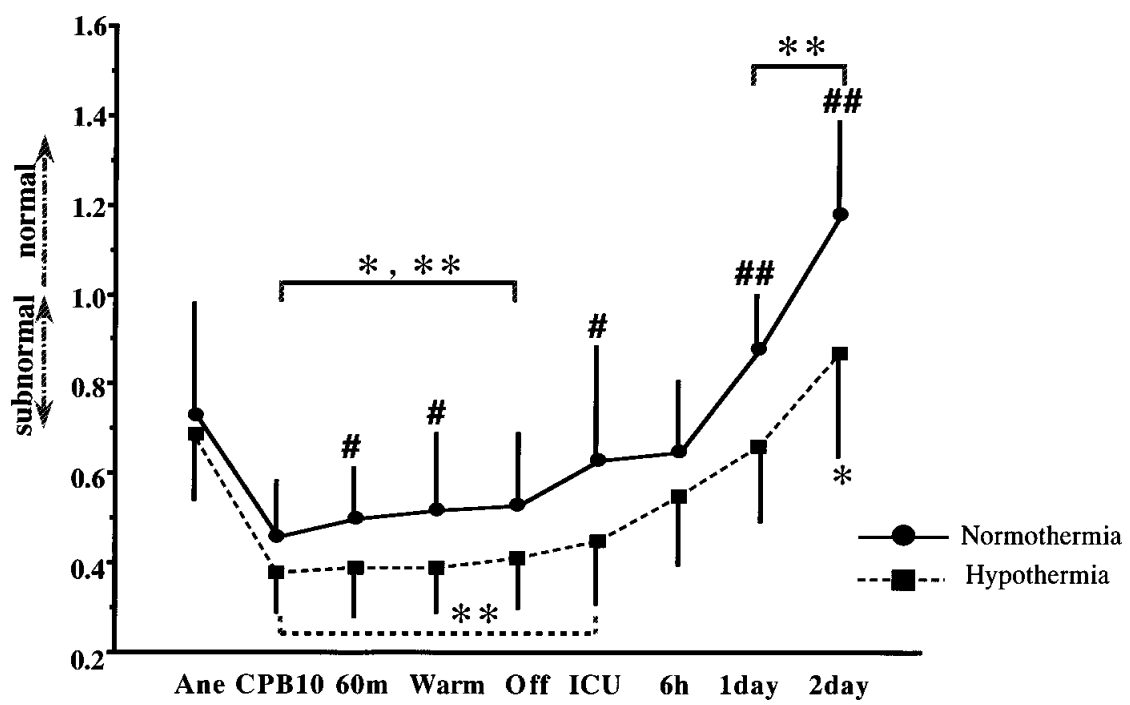

Fig 1. The AKBR in both groups decreased after the onset of CPB and continued to remain at a significantly low level throughout $\mathrm{CPB}$. However, the AKBR in the normothermic group was better than that of the hypothermic group. ${ }^{*} P$ $<.05, * * P<.01$ vs anesthesia; $\# P<.05$, \#\#P<.01 between 2 groups. Ane, After anesthesia; $C P B 10,10$ minutes after $\mathrm{CPB} ; 60 \mathrm{~m}, 60$ minutes after $\mathrm{CPB}$; Warm, during the warming period in the hypothermic or at the aortic declamping in the normothermic group; Off, end of CPB; ICU, ICU admission; $6 h, 6$ hours in ICU; 1day, first postoperative day; 2 day, second day.

Table II. Hepatic blood flow

\begin{tabular}{|c|c|c|c|c|c|c|}
\hline & \multicolumn{3}{|c|}{ Hepatic blood flow ( $\mathrm{mL} / \mathrm{min})$} & \multicolumn{3}{|c|}{$\%$ value of $C O$} \\
\hline & Pre-CPB & During $C P B$ & Post-CPB & Pre-CPB & During $C P B$ & Post-CPB \\
\hline Normothermia & $499 \pm 111$ & $479 \pm 139$ & $563 \pm 182$ & $12 \pm 3$ & $12 \pm 3$ & $11 \pm 6$ \\
\hline Hypothermia & $476 \pm 156$ & $491 \pm 147$ & $560 \pm 202$ & $13 \pm 4$ & $11 \pm 4$ & $11 \pm 7$ \\
\hline
\end{tabular}

No significance among Pre-, During, and Post-CPB for either group. No significance between 2 groups. CO, Cardiac output.

Oxygen saturation of arterial, mixed venous, and hepatic venous blood. Samples were obtained from the radial arterial, hepatic venous, and the distal tip of the Swan-Ganz catheters. Arterial $\left(\mathrm{SaO}_{2}\right)$, mixed venous $\left(\mathrm{SvO}_{2}\right)$ and hepatic venous $\mathrm{O}_{2}$ saturation $\left(\mathrm{ShvO}_{2}\right)$ levels were measured at the same 9 time points described above for the ketone body ratio measurements. Blood gas analyses were performed with the Stat Profile Ultima device (Nova Biomedical, Waltham, Mass).

Other blood samples. Blood samples for measuring alanine aminotransferase (ALT), rapid turnover proteins (transferrin and transthyretin), ammonia, and tumor necrosis factor- $\alpha$ (TNF- $\alpha)$ levels were withdrawn from the hepatic venous catheter and transferred to appropriate sample tubes. The samples were taken after the induction of anesthesia, at the termination of the CPB, and at the time of admission to the ICU. The lactate level in the hepatic venous blood was also measured at the same 9 time points described above for ketone body ratio measurements. All of the blood samples, including the samples that were taken for the measurement of
ICG clearance, were immediately centrifuged. The plasma was stored at $-70^{\circ} \mathrm{C}$ for laboratory assay. All plasma samples were forwarded to the laboratory assay company (Sumitomo Bio-Science, Omiya, Japan). Transferrin and transthyretin levels were measured by nephelometry. Ammonia and TNF$\alpha$ levels were measured with enzyme immunoassays. The lactate level was also measured enzymatically.

Patients were excluded from this study for the following reasons: (1) emergency cases, (2) history of previous cardiac operations, (3) coexistence of valvular heart disease, (4) renal failure, (5) cerebrovascular or lung disease, and (6) hepatic disease.

Statistical analysis. All data are expressed as the mean \pm standard deviation. Comparisons of the patient characteristics were made with the Student $t$ test or $\chi^{2}$ test. Two-way analysis of variance with adjustment for repeated measures was used for intergroup comparison. The calculated significant probabilities were adjusted by the Dunnett multicomparison method to control type I errors. Analysis of variance with Bonferroni/Dunn multicomparison method as a post hoc test 


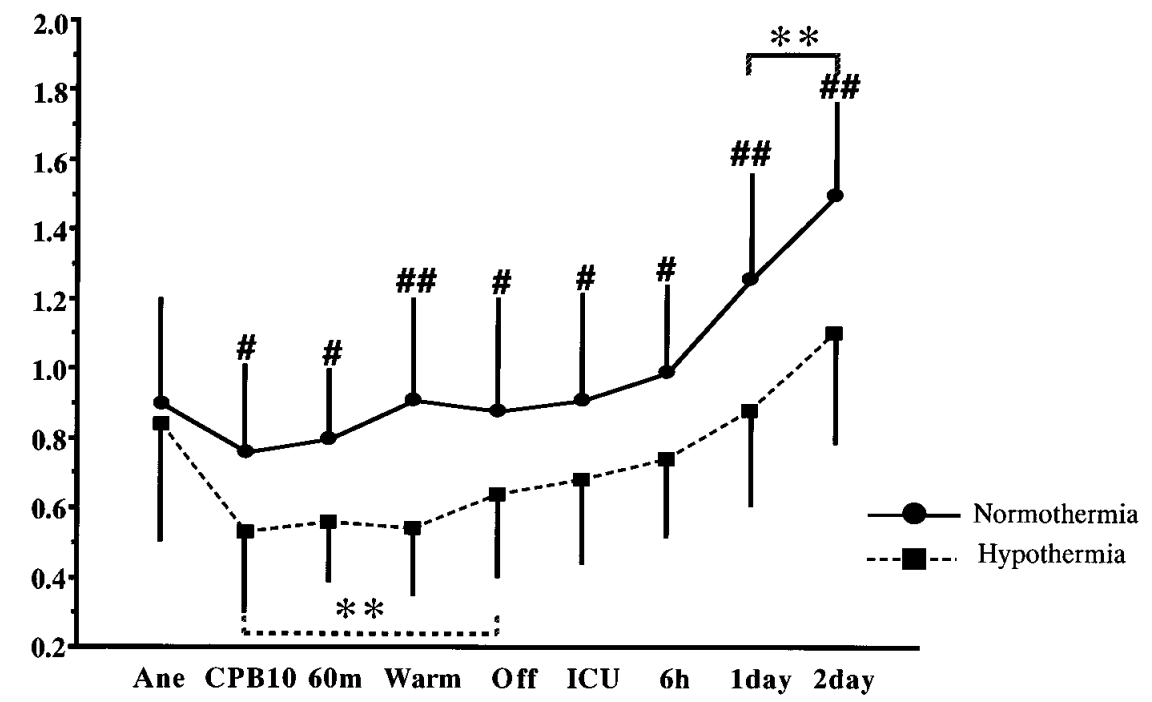

Fig 2. The reduction in the HKBR of the normothermic group was not significant to the value after anesthesia $($ Ane). The ratios were statistically better than those of the hypothermic group throughout the measurement period. $* * P<.01$ vs anesthesia; $\# P<.05$, \#\#P<.01 between 2 groups. $C P B 10,10$ minutes after the CPB; $60 \mathrm{~m}, 60$ minutes after $\mathrm{CPB}$; Warm, during the warming period in the hypothermic group or at the aortic declamping in the normothermic group; Off, end of CPB; ICU, ICU admission; $6 h, 6$ hours in the ICU; 1day, first postoperative day; 2 day, second day.

Table III. Oxygen metabolism (\%) and lactate levels (mmol/L)

\begin{tabular}{|c|c|c|c|c|c|c|c|c|c|}
\hline & Anesthesia & $\begin{array}{c}C P B \\
10 \mathrm{~min}\end{array}$ & $\begin{array}{c}C P B \\
60 \mathrm{~min}\end{array}$ & $\begin{array}{c}\text { Warm } \\
\text { (aorta unclamp) }\end{array}$ & $\begin{array}{r}C P B \\
\text { off }\end{array}$ & $I C U$ & $I C U 6 h$ & 1 day & 2 day \\
\hline \multicolumn{10}{|c|}{ Normothermia } \\
\hline $\mathrm{SaO}_{2}$ & 100 & 100 & 100 & 100 & 100 & 100 & $99 \pm 0.6$ & $99 \pm 1.0$ & $98 \pm 3$ \\
\hline $\mathrm{SvO}_{2}$ & $84 \pm 6$ & $81 \pm 4$ & $77 \pm 3 * 8$ & $77 \pm 4^{*}$ & $83 \pm 5$ & $84 \pm 5$ & $69 \pm 8^{\dagger}$ & $70 \pm 7^{\dagger}$ & $69 \pm 10^{*}$ \\
\hline $\mathrm{ShvO}_{2}^{2}$ & $80 \pm 7$ & $39 \pm 16^{\dagger+}$ & $41 \pm 13^{\dagger \S}$ & $36 \pm 13^{\dagger}$ & $65 \pm 11^{\dagger \S}$ & $74 \pm 12$ & $66 \pm 7^{\dagger}$ & $69 \pm 9^{\dagger}$ & $60 \pm 16$ \\
\hline Lactate & $0.8 \pm 0.6$ & $1.7 \pm 0.9^{\dagger}$ & $2.0 \pm 1.3^{\dagger}$ & $2.3 \pm 1.5^{\dagger}$ & $3.1 \pm 2.1^{\dagger}$ & $3.4 \pm 2.1^{\dagger}$ & $3.9 \pm 2.0^{\dagger}$ & $1.8 \pm 1.6^{\dagger}$ & $1.3 \pm 0.3^{*}$ \\
\hline \multicolumn{10}{|c|}{ Hypothermia } \\
\hline $\mathrm{SaO}_{2}$ & 100 & 100 & 100 & 100 & 100 & 100 & $99 \pm 0.8$ & $99 \pm 1.4$ & $98 \pm 1.6$ \\
\hline $\mathrm{SvO}_{2}$ & $83 \pm 5$ & $83 \pm 12$ & $86 \pm 5$ & $77 \pm 3^{\dagger}$ & $83 \pm 6$ & $83 \pm 6$ & $71 \pm 8^{\dagger}$ & $70 \pm 7^{\dagger}$ & $70 \pm 5^{\dagger}$ \\
\hline $\mathrm{ShvO}_{2}$ & $81 \pm 12$ & $58 \pm 20^{\dagger}$ & $61 \pm 18^{\dagger}$ & $46 \pm 22^{\dagger}$ & $76 \pm 6$ & $77 \pm 11$ & $71 \pm 13^{*}$ & $69 \pm 12$ & $69 \pm 6$ \\
\hline Lactate & $0.8 \pm 0.8$ & $2.1 \pm 0.7^{\dagger}$ & $2.5 \pm 0.8^{\dagger}$ & $2.7 \pm 1.2^{\dagger}$ & $4.1 \pm 1.0^{\dagger}$ & $4.2 \pm 1.2^{\dagger}$ & $5.3 \pm 1.5^{\dagger}$ & $2.4 \pm 0.6^{\dagger}$ & $1.6 \pm 0.4^{\dagger}$ \\
\hline
\end{tabular}

$\mathrm{SaO}_{2}$, Arterial oxygen saturation; $\mathrm{SvO}_{2}$, mixed venous oxygen saturation; $\mathrm{Shvo}_{2}$, hepatic venous oxygen saturation.

$* P<.05$ versus anesthesia.

${ }^{\dagger} P<.01$ versus anesthesia.

$\stackrel{\square}{P}<.05$ between normothermia and hypothermia.

$\S P<.01$ between normothermia and hypothermia

was used for intragroup comparison. Analyses were performed with SPSS 6.1 (SPSS Inc, Chicago, Ill) for the Macintosh PowerMac (Apple Computer, Cupertino, Calif).

\section{Results}

The baseline characteristics of the study participants are listed in Table I. The groups were matched with regard to all preoperative demographic and operative variables.
Hepatic blood flow. Hepatic blood flow and its percentage of the cardiac output are listed for the 2 groups in Table II. The data did not show any significant differences among the pre-CPB, during $\mathrm{CPB}$, and post$\mathrm{CPB}$ values for either group. Values for corresponding periods between the 2 groups also showed no statistical differences.

AKBRs and HKBRs (Figs 1 and 2). The values of AKBR after the induction of anesthesia were $0.73 \pm$ 
0.27 for the normothermic and $0.69 \pm 0.15$ for the hypothermic group, which were lower limit of normal (normal range, $>1.0$; subnormal range, 0.7-1.0). Irrespective of the perfusion temperature $\left(36.5^{\circ} \mathrm{C}\right.$ or $\left.30^{\circ} \mathrm{C}\right)$, the AKBR decreased significantly after the onset of the CPB $(P<.01)$. The AKBRs in both groups continued to remain at a significantly low level throughout the CPB $(P<.01$ to .05 vs after anesthesia). The AKBR of the hypothermic group did not return to a normal level until the final measurement performed on the second postoperative day. However, the AKBR in the normothermic group was better than that of the hypothermic group during CPB throughout the measurement period $(P<.1$ or $P<.01$ to .05$)$ and returned to a normal level $(0.88 \pm 0.18)$ on the first postoperative day.

Although the same pattern of changes was observed for the HKBRs during and after CPB, the reduction in the HKBR of the normothermic group was not significantly different from the value after anesthesia. The ratios were statistically better than those of the hypothermic group throughout the measurement period after the initiation of CPB $(P<.01$ to .05$)$. The values returned to normal after the time of ICU admission in the normothermic group but did not return until first postoperative day in the hypothermic group.

Oxygen saturations of arterial, mixed venous and hepatic venous blood. The oxygen saturation data are listed in Table III. The $\mathrm{SaO}_{2}$ levels were nearly $100 \%$ in both groups throughout the period of measurement. In the hypothermic group the $\mathrm{SvO}_{2}$ values during the rewarming period and 6 hours after the time of ICU admission were statistically lower than the postanesthesia values $(P<.01)$. On the other hand, a significant reduction in $\mathrm{SvO}_{2}$ was additionally observed during the $\mathrm{CPB}$ in the normothermic group $(P<.05)$. The $\mathrm{SvO}_{2}$ values in both groups were almost identical for corresponding time periods except for the statistically lower value obtained 60 minutes after the induction of the CPB in the normothermic group $(P<.01)$. The $\mathrm{ShvO}_{2}$ levels during the $\mathrm{CPB}$ were significantly lower than the postanesthesia levels in both groups $(P<.01)$. The reductions in the $\mathrm{ShvO}_{2}$ levels of the normothermic group were statistically significant at 10 and 60 minutes after the initiation of CPB and at the cessation of CPB compared with the values of hypothermic group $(P<.01$ to .05$)$. However, no differences were observed for any other time periods.

Other blood samples. The blood sample results are listed in Table IV. The ALT and TNF- $\alpha$ values did not change after the CPB. However, the ammonia level increased after the CPB $(P<.01)$. The transferrin and
Table IV. Results of blood samples

\begin{tabular}{lccc}
\hline & Anesthesia & CPB off & ICU \\
\hline Normothermia & & & \\
ALT (IU/L) & $25 \pm 12$ & $18 \pm 7$ & $18 \pm 4$ \\
Transferrin $(\mathrm{mg} / \mathrm{dL})$ & $199 \pm 35$ & $122 \pm 24^{*}$ & $130 \pm 52^{*}$ \\
Transthyretin $(\mathrm{mg} / \mathrm{dL})$ & $19 \pm 6$ & $13 \pm 4^{*}$ & $15 \pm 4^{*}$ \\
Ammonia $(\mu \mathrm{g} / \mathrm{dL})$ & $12 \pm 5$ & $20 \pm 4^{*}$ & $21 \pm 9^{*}$ \\
TNF- $\alpha(\mathrm{pg} / \mathrm{mL})$ & $18 \pm 11$ & $17 \pm 10$ & $17 \pm 6$ \\
Hypothermia & & & \\
ALT $(\mathrm{IU} / \mathrm{L})$ & $26 \pm 11$ & $20 \pm 8$ & $22 \pm 9$ \\
Transferrin $(\mathrm{mg} / \mathrm{dL})$ & $191 \pm 18$ & $119 \pm 18^{*}$ & $132 \pm 48^{*}$ \\
Transthyretin $(\mathrm{mg} / \mathrm{dL})$ & $21 \pm 4$ & $13 \pm 4^{*}$ & $16 \pm 2^{*}$ \\
Ammonia $(\mu \mathrm{g} / \mathrm{dL})$ & $11 \pm 8$ & $25 \pm 13^{*}$ & $21 \pm 13^{*}$ \\
TNF- $\alpha(\mathrm{pg} / \mathrm{mL})$ & $14 \pm 5$ & $20 \pm 15$ & $18 \pm 9$ \\
\hline
\end{tabular}

$* P<.01$ vs anesthesia. No significance between 2 groups.

transthyretin levels decreased after $\mathrm{CPB}$ and at the time of ICU admission $(P<.01)$. However, no differences between the normothermic and hypothermic groups were observed for corresponding time periods in the above measurements. The lactate value increased promptly after the initiation of the $\mathrm{CPB}$ and continued throughout the measuring periods $(P<.01$ to .05$)$ in both groups (Table III). The levels in the normothermic group were somewhat lower than those of the hypothermic group, but the difference was not statistically significant.

\section{Discussion}

Sufficient oxygen delivery to meet organ demands is an important factor for protecting the organs during $\mathrm{CPB}$. Systemic hypothermia during $\mathrm{CPB}$ has been regarded as an essential measure that offers some degree of organ protection. ${ }^{13}$ However, some disadvantages of hypothermic CPB have been suggested, ${ }^{13}$ and the use of normothermic CPB has been reported to confer advantages over conventional hypothermic CPB. ${ }^{14-16}$ Several studies have been performed on the vulnerability of the brain to ischemia during normothermic CPB. ${ }^{17,18}$ However, few data are available on the effect of normothermic and hypothermic perfusion on the liver.

This study was performed in patients with a single condition and without evidence of congestive heart failure or hepatic disease, so that we could examine patients who had a normal liver and avoid differences of preoperative liver function. The study shows that perfusion temperature does not alter hepatic blood flow. Mathie and colleagues ${ }^{6}$ investigated the effects of different perfusion temperatures and of pulsed versus nonpulsed perfusion on hepatic blood flow and came to the same conclusion. Waldhausen and colleagues ${ }^{3}$ also concluded that normal blood flow could be maintained 
at a flow rate of $2.2 \mathrm{~L} \cdot \mathrm{min}^{-1} \cdot \mathrm{m}^{-2}$ during $\mathrm{CPB}$. Because the arterial oxygen saturation and hepatic blood flow in both the normothermic and the hypothermic groups were identical, the value of hepatic venous saturation was remarkably reduced in the normothermic group, indicating that a larger amount of oxygen was extracted in normothermic livers than in hypothermic livers. Koizumi ${ }^{19}$ examined experimental dog models and concluded that hepatic blood flow was slightly reduced during $\mathrm{CPB}$, irrespective of perfusion temperature, as a result of the exclusive reduction in portal venous blood flow. However, Koizumi found that hepatic venous oxygen uptake was well maintained by an increase in the oxygen uptake ratio. Another investigation by Yamada and colleagues ${ }^{5}$ involving Doppler measurements of portal venous flow in human beings concluded differently. In Yamada's study no reductions in portal venous flow were observed throughout CPB.

The reduction of acetoacetate to 3-hydroxybutyrate is a key metabolic reaction that takes place within liver mitochondria and involves the production of energyrich ketone bodies. The ratio of these 2 acids is termed the ketone body ratio and is regarded as a marker of hepatic energy or the redox potential of the liver mitochondria. ${ }^{7}$ This theory is based on the fact that the equilibrium between the concentrations of acetoacetate and 3-hydroxybutyrate reflects the ratio of $\mathrm{NAD}^{+} / \mathrm{NADH}$ (oxidized nicotinamide adenine dinucleotide/reduced nicotinamide adenine dinucleotide dehydrogenase) in the mitochondria. Recent studies of the utility of the AKBR have been called into question. In anhepatic phase (in liver transplantation, during clamping of hepatic artery and portal vein in hepatectomy), each of the 2 types of ketone body is metabolized to a different extent in extrahepatic tissues. These results were reported by Matsushita and colleagues. ${ }^{20}$ In this study, however, the livers were always perfused and we also measured the hepatic ketone body ratio, which is more accurate and less influenced by metabolism in extrahepatic tissues. ${ }^{21}$

The AKBR value before CPB was expected to be more than 1.0. However, the data obtained in both groups were at the lower limit of normal and were considered to be influenced by anesthesia, because both groups demonstrated normal values at the final measurement. The pattern of AKBR changes in the normothermic CPB group was better than that of the hypothermic group. The higher values and earlier recovery of the AKBR value during and after the $\mathrm{CPB}$ suggest that the metabolic integrity of the liver was better maintained in the normothermic group. As the ketone bodies newly produced by the liver are transported to the right side of the heart via the hepatic vein, HKBRs reflect more accurately. ${ }^{21}$

The HKBR values obtained from the hepatic venous blood showed a clearer benefit to the mitochondrial redox potential in the normothermic $\mathrm{CPB}$ group. The decrease of HKBR ratios during CPB was small (not significant), and recovery was faster than in the hypothermic group. These findings suggest that normothermic perfusion is preferable with regard to the maintenance of liver metabolism and liver protection during CPB. Hypothermic perfusion appears to have suppressed the liver metabolic cycle during $\mathrm{CPB}$ and delayed the restoration of normal liver function after CPB. The reduction in $\mathrm{ShvO}_{2}$ values observed during normothermic CPB reflected the extraction of oxygen but was not low enough to cause ischemia. Takano and colleagues ${ }^{22}$ reported that $\mathrm{ShvO}_{2}$ is a useful indicator for predicting acute hepatic failure after Fontan operations. A critical value was set at below $25 \%$ during the first 24 hours after the operation. In this study none of the patients exhibited a value below $25 \%$ after the operation, but 3 patients in the normothermic group and 2 patients (during the warming period) in the hypothermic group exhibited a value of less than $25 \%$ for a short period of time during $\mathrm{CPB}$. Of course, another important factor leading to liver damage, central venous pressure, was much lower in this study than post-Fontan operation values. Events of reduced $\mathrm{Shvo}_{2}$ were not considered detrimental to cause malfunction of the liver in the normothermic $\mathrm{CPB}$.

ALT is a common leaking enzyme that is released by destroyed hepatocytes. Rapid turnover proteins (transferrin and transthyretin) produced by hepatocytes are synthesized on polyribosomes bound to the rough endoplasmic reticulum. A decrease in the concentration of these proteins reflects a decrease in hepatic synthesis. Amino acids are metabolized to ammonia and urea by the Krebs-Henseleit urea cycle in the liver. An increase in serum ammonia levels represents a failure of the Krebs-Henseleit cycle. TNF- $\alpha$ is one of the cytokines released by activated Kupffer cells and acts as a trigger for liver damage after ischemia. Lactate is an end product of glycogen in the muscle and is metabolized in the liver, mainly by gluconeogenesis. An increase in lactate levels indicates metabolic failure in the liver. Overall, the results concerning the above indicators suggest that some early changes in liver functioning might be occurring, but no significant differences were detected between the 2 groups. The ketone body ratios (particularly HKBR) were, however, sensitive enough to show a difference in liver function. The 
abnormalities of other indicators measured in this study of course occurred under the circumstance of a low AKBR (not necessarily induced by liver disease, but also by systemic dysfunction such as shock, hypoxia, and hemodilution). ${ }^{23,24}$ The AKBR indicates the hepatic energy reserve but does not always reflect the magnitude of hepatocellular damage or particular deficits among several aspects of liver function. Normal hepatocytes can produce additional energy as compensation for damaged cells. However, failure of compensation finally results in lethal dysfunction and liver damage. This might be a reason why there was a difference in results between the usual liver function markers and the AKBR. The hepatic damage induced by CPB is usually small in normal livers and cannot be considered as a serious side effect. However, the low ketone body ratio during CPB may induce serious hepatic complications in patients with pre-existing liver damage.

Recently, we ${ }^{25}$ and others ${ }^{26,27}$ investigated the influence of CPB temperature on circulatory pathophysiology. The activation of blood components and various vasoactive substances did not vary with the perfusion temperature $\left(36^{\circ} \mathrm{C}\right.$ or $\left.30^{\circ} \mathrm{C}\right)$. None of the above investigators have shown that normothermic $\mathrm{CPB}$ results in a better physiologic body response, but several clinical advantages have been documented, including the preservation of coagulation processes and a reduction in bleeding, hemodynamic stability, and a shorter period of intubation. ${ }^{14-16,25}$ An impaired turnover of the tricarboxylic cycle has a large effect on glucose metabolism, so a good theoretical argument exists for using ketone body ratio to reflect the metabolic integrity of the entire body. ${ }^{7}$ The reduction of energy in hepatocytes decreases energy supply at the mitochondria in the other organs. A decrease in this ratio inevitably leads to the destruction of muscle protein, which results in the accumulation of lactate and amino acids in the blood. Considerable evidence exists suggesting that AKBR is closely correlated with hemorrhagic shock, hypoxia, and hemodilution. ${ }^{23,24}$ It has also been recognized that the hepatic mitochondria influence the role of platelets, neutrophils, and lymphocytes. ${ }^{28}$ Nomoto and colleagues ${ }^{8}$ demonstrated that in patients undergoing cardiac surgery requiring prolonged respiratory or circulatory support, AKBR recovery was slower than in normal convalescent patients. Complement activation has been reported to be related to the morbidity associated with cardiac surgery. ${ }^{13}$ Influence of hepatic mitochondrial redox state on complement biosynthesis and activation was also investigated during and after CPB. The complement activation and consumption were significantly increased in the low AKBR rates of patients. ${ }^{9}$
In view of this result, our data suggest that normothermic CPB is not only advantageous for glucose and oxygen metabolism in tissues, but also leads to a better systemic response to the CPB.

The use of moderate systemic hypothermia has been believed to be the most important measure in protecting vital organs during CPB. However, recent advances in CPB instruments and equipment (oxygenators and efficient pumps), which have increased the biocompatibility of these devices, improved oxygenation, and increased blood flow, may have altered the importance of hypothermic perfusion.

We held a consultation of data analysis with the statistician Dr Katunori Shimada (STATZ Corporation). We thank Mr Kamiyashiki and Mr Someya for their technical assistance (Division of Medical Engineering in our institute).

Received for publication May 10, 2000; revisions requested Sept 5, 2000; revisions received Sept 18, 2000; accepted for publication Dec 1, 2000.

Address for reprints: Kazuhiro Hashimoto, MD, Saitama Cardiovascular and Respiratory Center, Department of Cardiovascular Surgery, 1696 Itai, Konan-machi, Osatogun, Saitama-ken, 360-0105, Japan (E-mail: drs-hashimoto @mti.biglobe.ne.jp).

\section{REFERENCES}

1. Wang MJ, Chao A, Huang CH, Tsai CH, Lin FY, Wang SS, et al. Hyperbilirubinemia after cardiac operation: incidence, risk factors, and clinical significance $\mathrm{J}$ Thorac Cardiovasc Surg 1994;108:429-36.

2. Ooi T. The evaluation of hepatic function during extracorporeal circulation using indocyanine green. J Jpn Assoc Thorac Surg 1982;30:325-41.

3. Waldhausen JA, Lombardo CR, McFarland JA, Cornell WP, Morrow AG. Studies of hepatic blood flow and oxygen consumption during total cardiopulmonary bypass. Surgery 1959;46:1118-27.

4. Lepert R, Orlowski T, Madry K. Hepatic blood flow, oxygen consumption and vascular resistance in the liver during extracorporeal circulation with hemodilution in normothermia. Acta Med Pol 1977;18:29-45.

5. Yamada T, Nomoto S, Aota M, Nishimura K, Matsuda K, Ban T. Hepatic circulation during nonpulsatile cardiopulmonary bypass. ASAIO J 1995;41:M294-7.

6. Mathie RT, Ohri SK, Batten JJ, Peters AM, Keogh BE. Hepatic blood flow during cardiopulmonary bypass operations: the effect of temperature and pulsatility. J Thorac Cardiovasc Surg 1997;114:292-3.

7. Ozawa K, Aoyama H, Yasuda K, Shimahara Y, Nakatani T, Tanaka J, et al. Metabolic abnormalities associated with postoperative organ failure. Arch Surg 1983;118:1245-51.

8. Nomoto S, Shimahara Y, Kumada K, Ogino H, Okamoto Y, Ban T. Arterial ketone body ratio during and after cardiopulmonary bypass. J Thorac Cardiovasc Surg 1992;103:1164-7. 
9. Nomoto S, Shimahara Y, Kumada K, Okamoto Y, Ban T. Influence of hepatic mitochondrial redox state on complement biosynthesis and activation during and after cardiopulmonary bypass operations. Eur J Cardiothorac Surg 1996;10:273-8.

10. Takahashi M, Ueda K, Tabata R, Iwata S, Ozawa K, Uno S, et al. Arterial ketone body ratio as a prognostic indicator in acute heart failure. J Lab Clin Med 1997;129:72-80.

11. Kiyama H. Significance of arterial ketone body ratio as a parameter of oxygen metabolism in cardiac surgery. J Jpn Assoc Thorac Surg 1997;45:1525-31.

12. Winkler K, Larsen JA, Munkner T, Tygstrup N. Determination of the hepatic blood flow in man by simultaneous use of five test substances measured in two parts of the liver. Scand J Clin Lab Invest 1965;17:423-32.

13. Kirklin JW, Barratt-Boyes BG. Hypothermia, circulatory arrest, and cardiopulmonary bypass. In: Cardiac surgery. 2nd ed. New York: Churchill Livingstone; 1993. p. 63-97.

14. Singh AK, Feng WC, Bert AA, Rotenberg FA. Warm body, cold heart surgery. Eur J Cardiothorac Surg 1993;7:225-30.

15. Tonz M, Mihaljevic T, Pasic M, von Segesser LK, Turina M. The warm versus cold perfusion controversy: a clinical comparative study. Eur J Cardiothorac Surg 1993;7:623-7.

16. The Warm Heart Investigators. Randomized trial of normothermic versus hypothermic coronary bypass surgery. Lancet 1994;343:559-63.

17. Cook DJ, Oliver WC, Orszulak TA, Daly RC. A prospective, randomized comparison of cerebral venous oxygen saturation during normothermic and hypothermic cardiopulmonary bypass. J Thorac Cardiovasc Surg 1994;107:1020-9.

18. Croughwell N, Smith LR, Quill T, Newman M, Greeley W, Kern $\mathrm{F}$, et al. The effect of temperature on cerebral metabolism and blood flow in adults during cardiopulmonary bypass. J Thorac Cardiovasc Surg 1992;103:549-54.

19. Koizumi M. Effects of cardiopulmonary bypass on hepatic circu- lation and hepatic oxygen metabolism under fentanyl anesthesia in beagles. Masui 1998;47:541-6.

20. Matsushita K, Kawasaki S, Makuuchi M. Arterial ketone body ratio in liver surgery. Hepatology 1994;20:331-5.

21. Terada Y, Eguchi Y, Chang YJ, Tabata R, Sakumoto H, Takehiro $\mathrm{O}$, et al. Ketone body ratios of the superior and inferior vena cava and of pulmonary arterial blood compared to that of arterial blood: central venous ketone body ratio as a substitute for the arterial ketone body ratio. Clin Chim Acta 1996;247:81-8.

22. Takano H, Matsuda H, Kadoba K, Kawata H, Sawa Y, Shimazaki $\mathrm{Y}$, et al. Monitoring of hepatic venous oxygen saturation for predicting acute liver dysfunction after Fontan operations. J Thorac Cardiovasc Surg 1994;108:700-8.

23. Ukikura M, Ida T, Ozawa K, Tobe T. The influence of hypoxia and hemorrhage upon adenylate energy charge and bile flow. Surg Gynecol Obstet 1979;149:346-52.

24. Yamamoto M, Tanaka J, Ozawa K, Tobe T. Significance of acetoacetate/beta-hydroxybutyrate ratio in arterial blood as an indicator of the severity of hemorrhagic shock. J Surg Res 1980;28:124-31.

25. Hashimoto K, Sasaki T, Hachiya T, Onoguchi K, Takakura H, Oshiumi M, et al. Influence of cardiopulmonary bypass temperature on circulatory pathophysiology and clinical outcomes. Jpn Circ J 2000;64:436-44.

26. Lehot JJ, Villard J, Piriz H, Philbin DM, Carry PY, Gauquelin G, et al. Hemodynamic and hormonal responses to hypothermic and normothermic cardiopulmonary bypass. J Cardiovasc Vasc Anesth 1992;6:132-9.

27. Frering B, Philip I, Dehoux M, Rolland C, Langlois JM, Desmonts JM. Circulating cytokines in patients undergoing normothermic cardiopulmonary bypass. J Thorac Cardiovasc Surg 1994;108:636-41.

28. Ozawa K. Liver surgery approached through the mitochondria: the redox theory in evolution. Tokyo: Medical Tribune; 1992.

\section{Timely}

The Journal of Thoracic and Cardiovascular Surgery delivers the information you need now. Articles usually appear within four months of acceptance. 